\title{
Early implantation of multiple spring coils for severe haemolysis after incomplete transcatheter occlusion of persistent arterial duct
}

\author{
Yiu-fai Cheung, Maurice P Leung, Kai-tung Chau
}

\begin{abstract}
An 18 month old girl with an angiographically measured ductus of $4.5 \mathrm{~mm}$ underwent transcatheter occlusion of the persistent arterial duct with a $17 \mathrm{~mm}$ Rashkind umbrella and an occluding spring coil. Severe intravascular haemolysis developed 20 hours later. Significant residual ductal leakage was noted and the residual duct measured $6 \mathrm{~mm}$. Previous underestimation might have been related to ductal spasm as a catheter was placed across the duct before angiography. The haemolysis was abolished within 48 hours by a previously unreported approach of antegrade transcatheter closure of the residual duct by multiple spring coils.
\end{abstract}

(Heart 1997;77:477-478)

Keywords: spring coil; haemolysis; persistent arterial duct

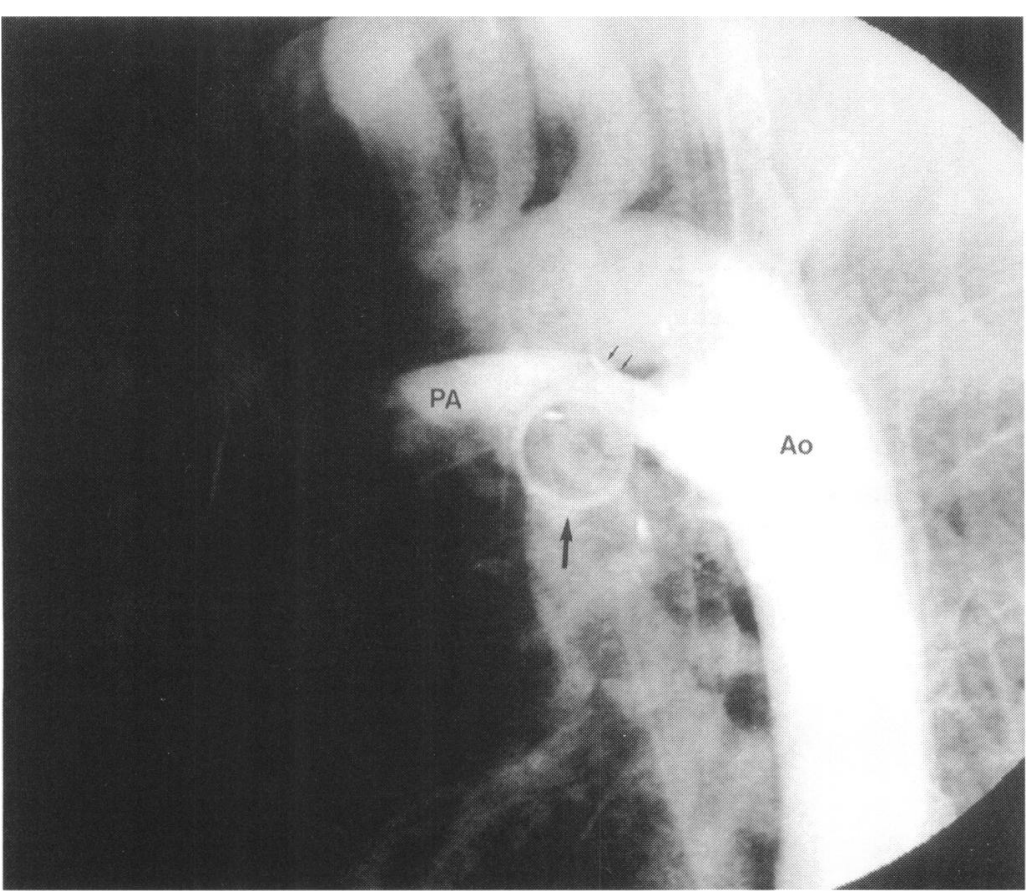

Figure 1 Lateral projection of the aortogram showing residual shunting in the form of a jet across the superior aspect of the Rashkind umbrella (thin arrows) and spring coil (bold arrow) after the first transcatheter occlusion. Ao, aorta; $P A$, pulmonary artery.
Severe mechanical haemolysis associated with residual ductal flow is uncommon after Rashkind umbrella occlusion. ${ }^{1}$ We describe a patient who had successful abolition of haemolysis by a previously unreported approach of antegrade transcatheter closure of the residual duct by multiple occluding spring coils.

\section{Case report}

A symptomatic 18 month old girl with a moderate size arterial duct underwent transcatheter ductal occlusion. The ductus measured $4.5 \mathrm{~mm}$ angiographically and the pulmonary to systemic flow ratio was $5 \cdot 2: 1$. A $17 \mathrm{~mm}$ Rashkind double umbrella was placed $^{2}$ (coils are considered for ductus $\leqslant 3 \mathrm{~mm}$ at our institution). Significant residual ductal leak across the superior border prompted retrograde placement ${ }^{3}$ of a $5 \mathrm{~cm} \times$ $8 \mathrm{~mm}$ Gianturco coil (MWCE-38-5-8, Cook Inc). The umbrella was not deployed until the coil was placed in situ for fear of dislodgement. The coil, however, failed to approximate tightly to the umbrella with significant protrusion into the main pulmonary artery. Repeated aortogram showed moderate reduction of the residual leakage and this was accepted.

Persistent severe intravascular haemolysis related to residual shunting was noted 20 hours later. A second transcatheter occlusion was attempted within 48 hours of the initial catheterisation. Significant residual ductal leakage was noted (fig 1 ) and the residual duct measured $6 \mathrm{~mm}$. Previous underestimation might be related to ductal spasm as a catheter was placed across the duct before angiography.

Three more Gianturco coils $5 \mathrm{~cm} \times 5 \mathrm{~mm}$ were placed using the antegrade approach. ${ }^{4}$ The catheters passed antegradely through the superior and lateral margins of the umbrella without difficulty. Repeated aortogram showed minimal residual shunting with dispersion of the contrast jet (fig 2). Intravascular haemolysis was abolished 16 hours after the second procedure. No residual leak or turbulent flow in the left pulmonary artery and the aorta was evident three weeks after the second occlusion. 


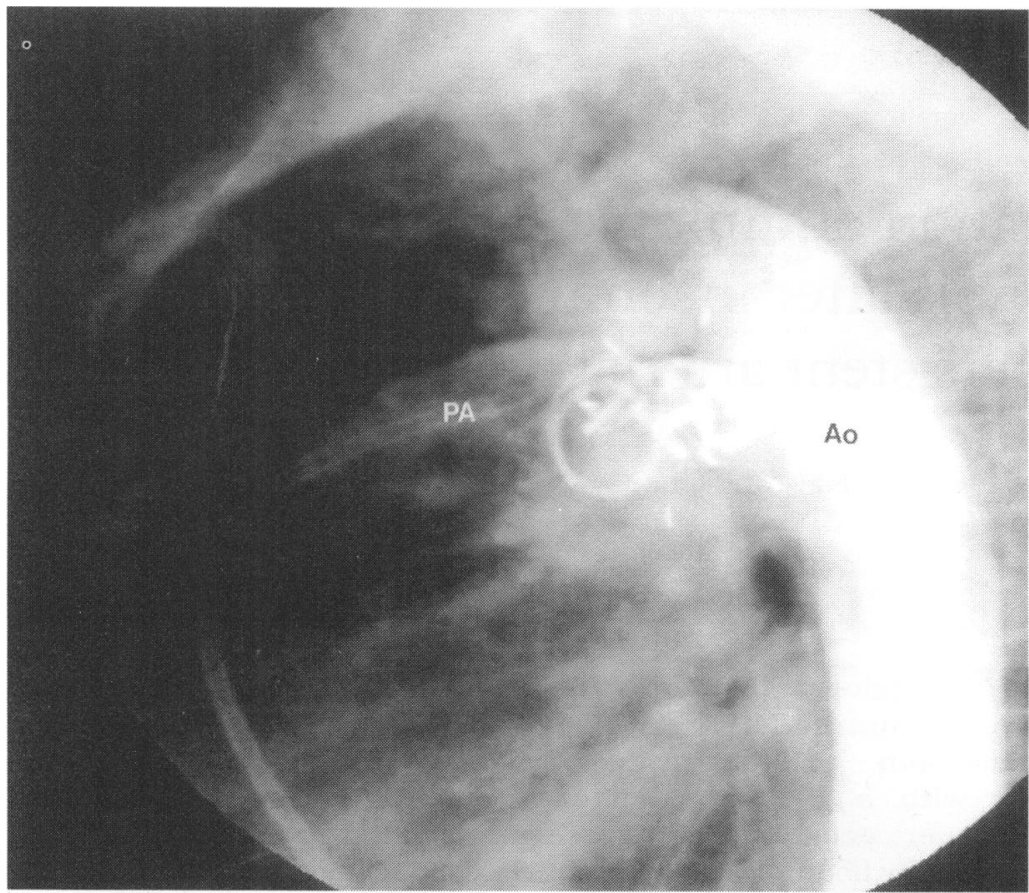

Figure 2 After placement of three more occluding spring coils, a repeat aortogram showed minimal residual shunting of the radiographic contrast in a dispersed fashion. Ao, aorta; $P A$, pulmonary artery. able. Our case illustrated that multiple spring coils could be safely deployed to occlude major residual shunt soon after incomplete transcatheter occlusion of persistent arterial duct. Our initial concern of dislodging the implanted Rashkind umbrella proved unnecessary.

Retrospectively, the delivery system at the pulmonary end prevented close approximation of the first coil onto the umbrella. During the second therapeutic intervention, two softtipped 5 French catheters could pass simultaneously through the residual duct without causing any movement of the umbrella. The natural spiralling ends of the coil enhanced its grip onto the umbrella with minimal traction force and a relatively low risk of embolisation. The occluding coils converted the high velocity leaking jet to a dispersed stream and completely abolished intravascular haemolysis.

We therefore recommend that early occlusion of a residual shunt by multiple coils is the treatment of choice when intravascular haemolysis occurs. It might be tempting to suggest that for large arterial ducts $(>5 \mathrm{~mm}$ ) with significant leakage after placement of a Rashkind device, multiple coils could be deployed immediately to abolish the residual shunt.

\section{Discussion}

The incidence of mechanical haemolysis after occlusion of the arterial duct by Rashkind umbrella is $0.5 \% .^{1}$ Intravascular haemolysis complicating spring coil occlusion has not been reported. The exact culprit in our patient is unknown, although the high velocity jet passing through the occluding devices probably contributed to the cellular destruction.

Early implantation of a second Rashkind device (six to 23 days), with or without removing the initially placed umbrella, has been successful. ${ }^{56}$ The risks of vascular damage and device dislodgement are, however, consider-
1 Report of the European Registry. Transcatheter occlusion of persistent arterial duct. Lancet 1992;340:1062-6.

2 Rashkind WJ, Mullins CE, Hellenbrand WE, Tait MA Nonsurgical closure of patent ductus arteriosus: clinical application of the Rashkind PDA occluder system. application of the Rashlation 1987;75:583-92

3 Lloyd TR, Fedderly R, Mendelsohn AM, Sandhu SK, Beekman RH. Transcatheter occlusion of patent ductus arteriosus with gianturco coils. Circulation 1993;88: 1412-20.

4 Hijazi ZM, Geggel RL. Results of anterograde transcatheter closure of patent ductus arteriosus using single or multiple gianturco coils. $A m \Im$ Cardiol 1994;74:925-9.

5 Grifka RG, O'Laughlin MP, Mullins CE. Late catheter removal of a Rashkind PDA occlusion device fo persistent hemolysis using a modified transseptal sheath. Cathet Cardiovas Diagn 1992;25:140-3.

6 Hayes AM, Redington AN, Rigby ML. Severe haemolysis after transcatheter duct occlusion: a non-surgical remedy. Br Heart F 1992;67:321-2. 